\title{
Choice of Method for Administration of Oxygen
}

\author{
I. D. GREEN,* M.B., M.R.C.P.
}

The need for carefully controlled continuous oxygen therapy for patients with chronic obstructive airways disease has been amply stated (Campbell, 1960; Hutchison et al., 1964). Further, it has been suggested that patients with cardiogenic shock require as high a concentration of oxygen as possible in the inspired air (MacKenzie et al., 1964). It is surprising, therefore, that, with the exception of the Ventimask, little or no information is provided by the manufacturers of the many devices at present available in regard to the concentrations of oxygen likely to be delivered to the patient. Few data have been published comparing the performance of these various pieces of equipment in an attempt to define which is the most appropriate to use in a given set of circumstances.

Campbell (1960) pointed out the danger of intermittent oxygen therapy and the need for continuous administration, and it is not uncommon for a patient to be treated continuously with oxygen for several days. Clearly, then, the method used should be comfortable for the patient and should interfere with his activities and those of his attendants as little as possible. This aspect of oxygen therapy has been largely ignored by those writing on the subject.

This paper describes the investigation of a number of methods of oxygen administration commonly employed. The aspects that have been particularly examined are: (1) how accurately the concentration of oxygen that each delivers can be predicted; (2) to what extent rebreathing occurs; and (3) how comfortable and convenient the methods are.

Recommendations are made about which device is likely to be the most appropriate one for the condition being treated. The methods that have been examined in detail are: (1) the Addis nasal cannula made by Portex Ltd. (Addis, 1963); (2) the Bardic nasal cannula made by Bard Inc.; (3) the Edinburgh mask made by British Oxygen Co. (Flenley et al., $1963)$; (4) the Ventimask made by Oxygenaire Ltd. (Campbell and Gebbie, 1966) ; (5) the Polymask made by British Oxygen Co. ; and (6) the Pneumask made by Oxygenaire Ltd.

\section{Methods}

\section{To Determine the Concentration of Oxygen Delivered}

No direct measurement could be made of the inspired oxygen concentration $\left(\mathrm{F}_{1} \mathrm{O}_{2}\right)$ when the nasal cannulae or the Edinburgh mask were worn. A method of human tomometry was therefore employed. Four normal men aged 28 to 34 acted as subjects. After an initial period of rest of 15 minutes each breathed in succession five mixtures of oxygen in nitrogen. The concentrations of oxygen ranged from 21 to $48 \%$. They breathed each gas for half an hour through a close-fitting oronasal mask. Over the last three minutes of each half-hour blood was withdrawn from an indwelling brachial artery catheter and analysed for its oxygen partial pressure (PaO, with a Clark electrode (S.D. $\pm 1.13 \mathrm{~mm}$. Hg) (Bishop, 1960). The $\mathrm{PaCO}_{2}$ was also measured with a Severinghaus electrode and compared with the resting value to ensure that no significant hyperventilation had occurred. A graph was then constructed for each subject relating $\mathrm{PaO}_{2}$ to the impaired oxygen con-

\footnotetext{
* Lecturer in Clinical Medicine, Department of Medicine, Queen Eliza-
} beth Hospital, University of Birmingham, Birmingham 15. centration as a percentage $\left(\mathrm{F}_{\mathrm{I}} \mathrm{O}_{2}\right)$. The same subjects then each wore a nasal cannula and the Edinburgh mask in turn, and the blood gases were again measured after the same length of time. (It had previously been shown that the two nasal cannulae gave identical results.) It was then possible to read from the subject's calibration curve what his $\mathrm{F}_{\mathrm{I}} \mathrm{O}_{2}$ had been. Three measurements were made at oxygen flows of 1,2 , and $41 . / \mathrm{min}$. for each of the devices.

The same procedure was carried out with the subjects wearing a $27 \%$ Ventimask with oxygen flows of 1,2 , and $41 . / \mathrm{min}$. As the mask was also assessed by direct measurement this served as a means of checking the accuracy of the blood gas method.

In two subjects wearing the nasal cannulae a comparison of the blood gas values was made during nose-breathing and mouth-breathing.

It was possible to make direct measurements of the $\mathrm{F}_{\mathrm{I}} \mathrm{O}_{2}$ with the three other masks. The same four subjects were used for the Ventimask. Four other normal men aged 23-31 years were used for the polyethylene masks. A respiratory mass spectrometer was used to obtain breath-by-breath measurements of the $\mathrm{F}_{\mathrm{I}} \mathrm{O}_{2}$ and $\mathrm{F}_{\mathrm{I}} \mathrm{CO}_{2}$ at $2,4,6$, and $8 \mathrm{l}$./min. of oxygen flow. The probe was inserted into a very short mouthpiece, a hole being cut in the two polyethylene masks for the purpose in such a way that it did not interfere with the mask's action. The nostrils were blocked. Recordings were made for three minutes at the end of half an hour at each level of oxygen flow. The minimum inspired $\mathrm{CO}_{2}$ concentration was measured from the traces and an estimate of the mean inspired $\mathrm{CO}_{2}$ was made.

\section{Comfort and Convenience}

Six male patients between the ages of 45 and 68 years took part to assess the comfort of the devices. Three suffered from chronic bronchitis and had had previous experience of wearing oxygen masks. At the time of the study they were in a quiescent phase of their disease and were not hypercarbic. The other three patients did not have pulmonary disease and had never worn a mask before.

Each patient wore the six devices for an hour each. The order in which they wore them was devised so that any one particular device was worn immediately after any other on as few occasions as possible. The patients were given at least three hours' rest between masks, and were never asked to assess more than two in one day. At the end of each hour they were given a piece of paper on which there was drawn a line $10 \mathrm{~cm}$. in length. This was marked at one end "No discomfort" and at the other "Intolerable discomfort." They were asked to put a cross on the line at a point which they thought represented the degree of discomfort they had experienced during the preceding hour. The distance in millimetres of this cross from the end marked "No discomfort" was taken as a measure of the degree of discomfort (Gedye et al., 1961). None of the six patients found any difficulty in understanding the method. They were also invited to make comments against or in favour of the device they had just tested.

Blood gas measurements were made in patients wearing some of the devices tested. 
Finally, three types of oxygen tents were evaluated; the findings are discussed below.

\section{Results}

Inspired Oxygen Concentration.-The calculated $\mathrm{F}_{\mathrm{I}} \mathrm{O}_{2}$ values for the nasal cannulae, the Edinburgh mask, and those of the Ventimask determined by the blood gas method are given in Table I. The mean values for nasal cannulae at 1, 2, and $41 . / \mathrm{min}$. were 27,31 and $36 \%$ respectively, for the Edinburgh mask 28, 33, and $37 \%$, and for the Ventimask 26, 27, and $28 \%$. By direct measurement the inspired oxygen concentrations provided by the Ventimask at all flows did not alter from $27 \%$ by more than $\pm 1 \%$ (Table II). The mean values for the Polymask were $36,52,70$, and $77 \%$ at $2,4,6$, and 8 1./min. flow, and for the Pneumask, 30, 50, 69, and $75 \%$.

TABLE I.-Inspired $O$, Concentrations of the Three Devices as Estimated From the Blood Gas Measurements of Subjects $A, B, C$, and $D$

\begin{tabular}{|c|c|c|c|c|c|c|}
\hline \multirow{2}{*}{$\begin{array}{c}\text { Method } \\
\text { of } \\
\text { Administration }\end{array}$} & \multirow{2}{*}{${ }_{\substack{\text { Flow } \\
\text { (1./min.) }}}^{\mathrm{O}_{\mathbf{2}}}$} & \multicolumn{5}{|c|}{ Inspired $\mathrm{O}_{2}$ Concentration } \\
\hline & & $\mathbf{A}$ & B & C & $\mathbf{D}$ & Means \\
\hline $\begin{array}{l}\text { Nasal cannula } \\
\text { Bdinburgh mask } \\
27 \% \text { ventimask }\end{array}$ & $\begin{array}{l}1 \\
2 \\
4 \\
1 \\
2 \\
4 \\
1 \\
2 \\
4\end{array}$ & $\begin{array}{l}27 \\
29 \\
36 \\
27 \\
29 \\
33 \\
27 \\
26 \\
28\end{array}$ & $\begin{array}{l}25 \\
29 \\
32 \\
26 \\
31 \\
39 \\
27 \\
26 \\
27\end{array}$ & $\begin{array}{l}29 \\
35 \\
39 \\
29 \\
36 \\
38 \\
27 \\
28 \\
28\end{array}$ & $\begin{array}{l}27 . \\
30 \\
38 \\
29 \\
35 \\
38 \\
24 \\
26 \\
27\end{array}$ & $\begin{array}{l}27 \\
31 \\
36 \\
28 \\
33 \\
37 \\
26 \\
27 \\
28\end{array}$ \\
\hline
\end{tabular}

TABLB II.-Inspired Oxygen Concentrations, as Measured Directly by the Mass Spectrometer, of Three of the Masks Worn by Subjects $A$ to $\mathrm{H}$

\begin{tabular}{|c|c|c|c|c|c|c|c|}
\hline & & \multirow{2}{*}{$\underset{\text { (1./min.) }}{\text { Olow }}$} & \multicolumn{5}{|c|}{ Inspired $\mathrm{O}_{2}$ Concentration } \\
\hline & & & $\mathbf{A}$ & $\mathbf{B}$ & $\mathbf{C}$ & $\mathbf{D}$ & Means \\
\hline Ventimask & $\cdots$ & $\begin{array}{l}2 \\
4 \\
6 \\
8\end{array}$ & $\begin{array}{l}27 \\
27 \\
28 \\
27\end{array}$ & $\begin{array}{l}27 \\
27 \\
27 \\
27\end{array}$ & $\begin{array}{l}26 \\
27 \\
27 \\
27\end{array}$ & $\begin{array}{l}27 \\
27 \\
27 \\
28\end{array}$ & $\begin{array}{l}27 \\
27 \\
27 \\
27\end{array}$ \\
\hline Pneumask & $\begin{array}{l}\cdots \\
\cdots\end{array}$ & $\begin{array}{l}2 \\
4 \\
6 \\
8 \\
2 \\
4 \\
6 \\
8\end{array}$ & $\begin{array}{c}\mathrm{B} \\
34 \\
49 \\
62 \\
72 \\
27 \\
46 \\
60 \\
61\end{array}$ & $\begin{array}{c}F \\
34 \\
49 \\
65 \\
76 \\
29 \\
49 \\
65 \\
72\end{array}$ & $\begin{array}{c}\text { G } \\
36 \\
56 \\
74 \\
77 \\
30 \\
52 \\
70 \\
76\end{array}$ & $\begin{array}{l}\mathbf{H} \\
39 \\
56 \\
78 \\
83 \\
32 \\
54 \\
82 \\
84\end{array}$ & $\begin{array}{l}36 \\
52 \\
70 \\
77 \\
30 \\
50 \\
69 \\
73\end{array}$ \\
\hline
\end{tabular}

Effect of Mouth-breathing.-In one subject the $\mathrm{PaO}_{2}$ was $10 \mathrm{~mm}$. $\mathrm{Hg}$ higher when he was nose-breathing than when breathing through the mouth wearing a nasal cannula. This corresponded to a difference of $1.4 \%$ in his $\mathrm{F}_{\mathrm{I}} \mathrm{O}_{2}$. In the other subject there was no difference.

Rebreathing.-The nasal cannulae could not have caused rebreathing. The Edinburgh mask was most unlikely to have done so, and that with the Ventimask proved to be negligible. The two polyethylene masks, on the other hand, caused a very significant degree of rebreathing. The mean minimum $\mathrm{F}_{\mathrm{I}} \mathrm{CO}_{2} \mathrm{~s}$ are given in Table III. The mean $\mathrm{F}_{\mathrm{I}} \mathrm{CO}_{2} \mathrm{~s}$ while the subjects were wearing the Pneumask at oxygen flows of over $4 \mathrm{l} . / \mathrm{min}$. were as high as $3 \%$.

TABLB III.-Minimum Inspired $O$, Concentrations in Subjects $E, F, G$ and $H$ Wearing the Pneumask and Polymask at Various Oxygen Flows

\begin{tabular}{|c|c|c|c|c|c|c|c|c|}
\hline \multirow[b]{2}{*}{$\begin{array}{l}\text { Og flow (1./min.) } \\
\text { Mean minimum } \mathrm{F}_{1} \mathrm{CO}_{2}\end{array}$} & \multicolumn{4}{|c|}{ Polymask } & \multicolumn{4}{|c|}{ Pneumask } \\
\hline & 2.5 & $\begin{array}{l}4 \\
0.8\end{array}$ & $\begin{array}{l}6 \\
0 \cdot 4\end{array}$ & $\begin{array}{l}8 \\
0.3\end{array}$ & $\begin{array}{l}2 \\
1 \cdot 3\end{array}$ & $\begin{array}{l}4 \\
1.8\end{array}$ & $\begin{array}{l}6 \\
1.9\end{array}$ & $\begin{array}{l}8 \\
1 \cdot 9\end{array}$ \\
\hline
\end{tabular}

\section{Comfort}

The distances of the patients' marks indicating their discomfiture from the end of the lines are shown as the "degree of discomfort" in Fig. 1, together with the mean values. All the patients clearly preferred the nasal cannulae. The order of preference for the masks was, Edinburgh mask, Polymask, Ventimask, and Pneumask. The mean scores for these masks were not greatly different from each other, however, and it would be wrong to place too much emphasis on this order. The additional remarks made by the patients were interesting. Such comments as "I didn't know I had it on," "Would wear it for any length of time with pleasure," "Very comfortable" were made about the cannulae. Almost without exception the patients made the point that they could get to their face and feed with comfort, and all three bronchitics noticed that they could spit. During the $\mathrm{F}_{\mathrm{r}} \mathrm{O}_{2}$ measurements it had been found necessary to humidify the gas with a Wright nebulizer, otherwise the subjects had a burning feeling in the nostrils at 4 $1 . / \mathrm{min}$. flow.

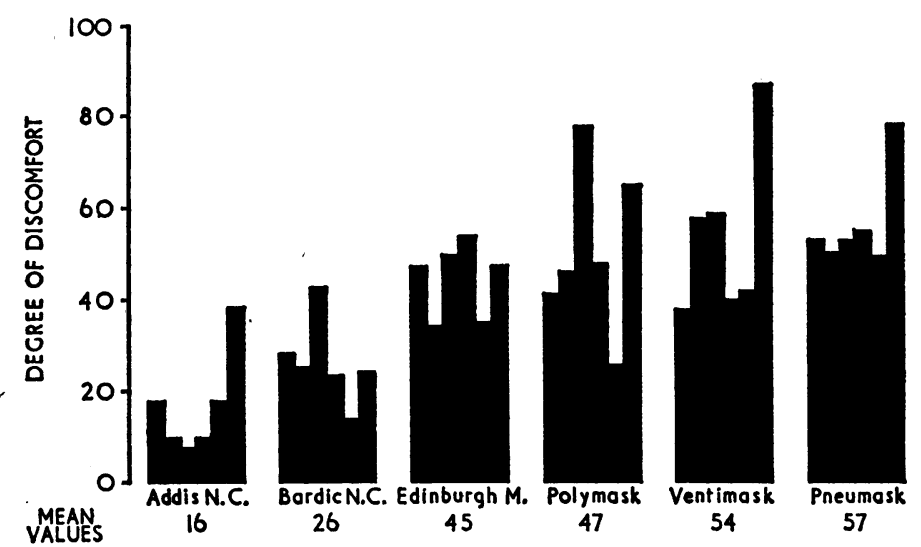

FIG. 1.-Results of six patients' assessment of the comfort of the six devices. Mean values are given-the higher the value the greater the
discomfort.

The main objections to the masks were that they all, with the exception of the Ventimask, became hot and sweaty. Most patients noticed discomfort over the bridge of the nose with the Edinburgh mask, the Polymask, and the Ventimask. They all obscured vision to some extent-probably not a serious drawback in a very ill patient. For some the polyethylene masks caused an uncomfortable flow of gas into the eyes. One patient commented that he liked the flow of gas from the Ventimask into his face, but another objected to it. By far the most common objection to the masks was that the patients were unable to get to their face.

\section{Discussion}

One striking finding which emerged from the trial was the patients' strong preference for the nasal cannulae. As regards their efficiency as a method, the cannulae proved as reliable as the Edinburgh mask in providing inspired oxygen concentrations between 25 and $39 \%$ at flows of 1 to $41 . / \mathrm{min}$. There was a subject-variation at each flow, this variation being related to the tidal volume. The larger this volume the lower the $\mathrm{F}_{\mathrm{I}} \mathrm{O}_{2}$ owing to greater dilution of the oxygen with inspired air. A patient with chronic obstructive airways will therefore tend to have an $\mathrm{F}_{1} \mathrm{O}_{3}$ near the upper end of each range given in Table $I$ for the cannulae and Edinburgh mask, and it should be remembered that such a patient wearing either of these devices may have an $\mathrm{F}_{\mathrm{I}} \mathrm{O}_{2}$ of as much as $30 \%$ at a flow of only $1 \mathrm{l} . / \mathrm{min}$.

In spite of the variation between subjects the nasal cannulae gave reproducible values in the same patient. Fig. 2 shows the results obtained in one patient with chronic hypercapnia whose blood gases were measured before and after being given oxygen for an hour by cannula at $4 \mathrm{1} . / \mathrm{min}$. on three succéssive days. 
The Ventimask gave a concentration of oxygen that could be predicted with great accuracy. Both methods of assessment gave similar results, which indicated that the indirect blood gas method was valid. Ventimasks are also available that provide an $\mathrm{Fr}_{\mathrm{r}_{2}}$ of 24,28 , and $35 \%$. Six of each of these have been tested in this unit with the mass spectrometer and have proved equally reliable.
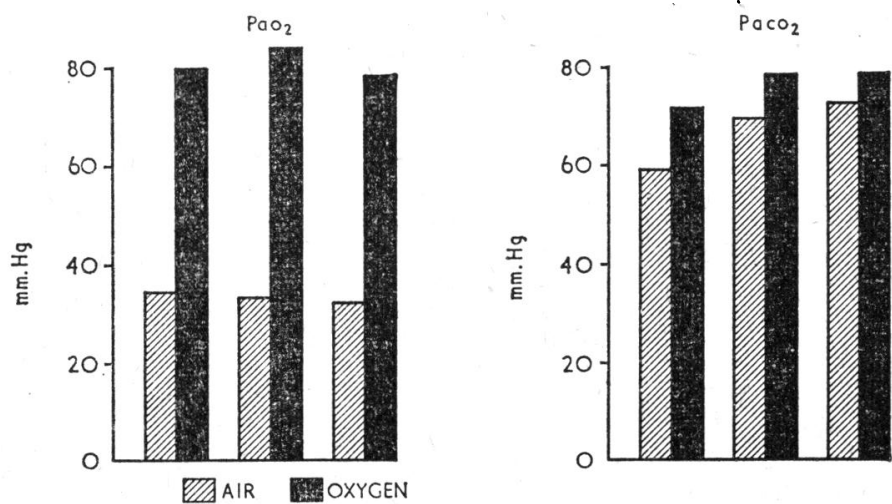

Frg. 2.- $\mathrm{PaO}_{3}$ and $\mathrm{PaCO} 2$ values in one patient measured on three successive days before and after oxygen through a normal cannula at 41 . $/ \mathrm{min}$.

The Ventimask's drawback is its lack of comfort. In order to assess whether its ability to control the $\mathrm{F}_{\mathrm{I}} \mathrm{O}_{2}$ accurately outweighs the patient's dislike, consideration has been given to the blood gas results of 38 patients, with chronic obstructive airways disease while in an acute exacerbation, who were treated with oxygen. The measurements were made when the patient was breathing air and after he had received oxygen at 1,2 , or $41 \mathrm{~min}$. through a nasal cannula. It can be seen in the oxygen/carbon dioxide diagram in Fig. 3 that if the airbreathing $\mathrm{PaCO}_{2}$ was below $60 \mathrm{~mm}$. $\mathrm{Hg}$ and the $\mathrm{PaO}_{2}$ above $45 \mathrm{~mm}$. Hg serious hypercapnia did not develop. With more pronounced blood gas disturbance before oxygen administra-

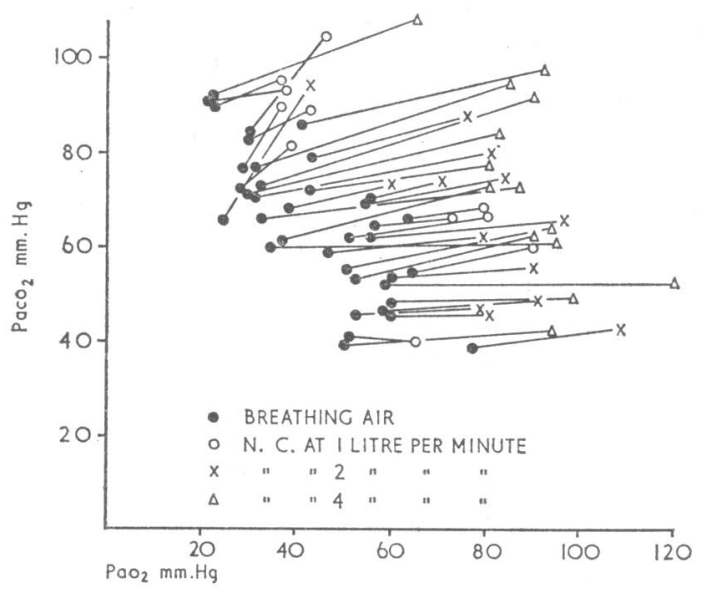

FIG. 3.-Changes in blood gases of 38 patients with obstructive airways disease when breathing oxygen through a nasal cannula at 1,2 , or $41 . / \mathrm{min}$.

tion a significant rise in $\mathrm{PaCO}_{2}$ did sometimes occur. In five patients with a flow of only $11 . / \mathrm{min}$. $\mathrm{PaCO}_{2}$ levels of over 80 $\mathrm{mm}$. $\mathrm{Hg}$ were reached. In each case the value on air had been above $70 \mathrm{~mm}$. $\mathrm{Hg}$ and the $\mathrm{PaO}_{2} 30 \mathrm{~mm}$. $\mathrm{Hg}$ or less. Clearly, then, these five patients required less oxygen than could be provided by a cannula to prevent serious hypercapnia and only the $24 \%$ Ventimask could have reliably done this. In spite of receiving a lower concentration of oxygen, however, three out of the five patients subsequently required assisted ventilation.

Little information is available on what is the lower level of $\mathrm{PaO}_{2}$ at which significant harm is done to vital organs. Until detailed studies have been made of regional function in com- bined anoxia and hypercapnia the safe level can only be guessed at. Hutchison et al. (1964) have suggested that the aim should be $50 \mathrm{~mm}$. $\mathrm{Hg}$. In none of the five patients given oxygen by nasal cannula at $11 . / \mathrm{min}$. did the $\mathrm{PaO}_{2}$ reach this figure, and the value with the $24 \%$ Ventimasks would therefore have been even lower. Nevertheless this mask may be of value in treating those patients with the most severely affected blood gases, especially when assisted ventilation is contraindicated or not available, and perhaps in conjunction with respiratory stimulants. The experience of this department suggests that the facility to deliver $28 \%$ or $35 \%$ with the same degree of accuracy is not necessary in the management of respiratory failure.

\section{Oxygen Tents}

With the exception of their use in very disturbed patients and children, oxygen tents have little value. There are available full-sized tents such as the Oxygenaire MK6 tent and the head tent described by Campbell and Gebbie (1966), that both work on the Venturi principle. These provide constant low concentrations of oxygen with few or no problems of humidity or temperature. However, they do enclose the patient so that he is less accessible and less easy to observe. Patients who need carefully controlled low concentrations of oxygen to prevent hypercapnia will be ill enough to require constant observation and attention, and are better treated with the $24 \%$ Ventimask.

At least $6 \mathrm{l} . / \mathrm{min}$. of oxygen must be delivered through the Polymask or Pneumask if they are not to be sucked on to the face. In Table II it can be seen that at least $60 \%$ oxygen will then be delivered to the patient. Such a high concentration would be likely to induce coma in a patient liable to hypercapnia. At $81 . / \mathrm{min}$. both masks provide about $80 \%$ oxygen. This makes them suitable for treating patients with cardiogenic shock and other conditions requiring a high $\mathrm{F}_{\mathrm{I}} \mathrm{O}_{2}$. Apart from the British Oxygen B.L.B. mask there is no other suitable device commercially available for giving higher concentrations to such patients. Nasal cannulae are unsuitable when a high concentration of oxygen is required, as flows of above $41 . / \mathrm{min}$. for long periods cause discomfort in the nose. It is therefore unlikely that concentrations in excess of about $40 \%$ can be achieved with them. No tents that we have tested have proved satisfactory for giving high concentrations of oxygen. The best that has been achieved by initial flushing and very careful sealing of the tent sides is about $50 \%$ inspired oxygen after an hour at $8 \mathrm{1} . / \mathrm{min}$.

\section{Care in Prescribing}

Any significant degree of rebreathing can be discounted with the cannulae, the Edinburgh mask, and the Ventimask. However, both polyethylene bag masks, in particular the Pneumask, are capable of producing very significant elevations of the $\mathrm{F}_{\mathrm{I}} \mathrm{CO}_{2}$. It should be noted that Table III gives only the minimum values of $\mathrm{F}_{\mathrm{ICO}}$, the mean values for the Pneumask being in the region of $3 \%$ in the working range. For this reason and because of the high concentrations of oxygen delivered by these two masks they should never be used in the treatment of patients with chronic obstructive airways disease or acute asthma.

A physician must prescribe oxygen with the same care as with any other dangerous drug. The dose should be written on the case sheet in the same way and the nursing staff made aware of its side-effects. The trial has indicated that to provide oxygen to a patient with respiratory failure and hypercapnia-the most difficult situation to prescribe for-the intelligent use of a nasal cannula and a $24 \%$ Ventimask, backed up by blood gas measurement or the measurement of the $\mathrm{PcO}_{3}$ by the rebreathing method, is all that is required, short of assisted ventilation. Furthermore, if such low concentrations 
as $24 \%$ are required, then it is likely that assisted ventilation will be necessary.

In treating patients with other forms of anoxia, when high concentrations of oxygen are needed, the only devices tested that are of value are the Polymask and Pneumask. In such cases the rebreathing they cause is probably not important provided there is no underlying chronic lung disease. There may well be need for the development of a mask that will provide even higher concentrations of oxygen. If such a device becomes available we will still have to prescribe with care because of the dangers of oxygen poisoning and absorption atelectasis.

\section{Summary}

A number of devices for delivering oxygen have been evaluated with special regard to what extent the concentration of oxygen they supply is predictable, whether or not they cause rebreathing, and how comfortable and convenient they are. The following conclusions have been drawn:

(1) Oxygen should always be prescribed with care and never left to the whims of untrained staff.

(2) Where there is a likelihood of serious hypercapnia, especially if there is a disturbance of consciousness, $\mathrm{PCO}_{2}$ measurements must be made by one or other of the available methods, and the concentration of oxygen the patient receives should be adjusted according to these measurements.

(3) The vast majority of patients with hypercapnia will tolerate oxygen at $1 \mathrm{litre} / \mathrm{min}$. through a nasal cannula, in- creasing flows being given if there is no serious rise in $\mathrm{PaCO}_{2}$ or a lowering of the level of consciousness.

(4) The oxygen must be adequately humidified if given by cannula.

(5) If serious hypercapnia is present-that is, in the region of $70 \mathrm{~mm} . \mathrm{Hg}-\mathrm{a} 24 \%$ Ventimask may be necessary, but such a patient is likely to need assisted ventilation.

(6) For the delivery of high concentrations of oxygen, but only when hypercapnia is not a problem, either the Polymask or the Pneumask is the most practical method available at present.

It is a pleasure to acknowledge the encouragement and helpful criticism of Professor J. M. Bishop and the technical assistance of Mrs. Anne Hollyhock and Miss Susan Pepper. I would also like to thank Miss Susan Wall for her help in the preparation of the text.

\section{REFERENCES}

Addis, G. J. (1963). Lancet, 1, 1084.

Bishop, M. (1960). Proc. roy. Soc. Med., 53, 177.

Campbell, E. J. M. (1960). Lancet, 2, 10.

Flenley, D. C., Hutchison, D. C. S., and Donald, K. W. (1963). Brit. med. f., 2, 1081.

Gedye, J. L., Aitken, R. C. B., and Ferres, H. M. (1961). Ibid., 1, 1828. Hutchison, D. C. S., Flenley, D. C., and Donald, K. W. (1964). Ibid., 2, 1159.

MacKenzie, G. J., Taylor, S. H., Flenley, D. C., McDonald, A. H., Staunton, H. P., and Donald, K. W. (1964). Lancet, 2, 825.

\section{Preliminary Communications}

\section{Phagocytosis by Polymorphonuclear Leucocytes from Patients with Renal Failure}

Brit. med. F., 1967, 3, 596-599

Acute infections are a common problem in the management of renal failure, though their incidence has not been investigated to the same extent as that of infection in other metabolic disorders such as diabetes mellitus. Experience of infective conditions in renal failure is summed up by Schreiner (1964), who states that "infection is the single leading cause of death even in the well-managed uraemic patient." The infective conditions to which this category of patients is prone are usually those caused by Staphylococcus pyogenes, Enterobacteriaceae, and Pseudomonas species. These pathogens are resisted principally by the non-specific defences of the host. It appeared worth while, therefore, to examine the phagocytic activity of polymorphonuclear leucocytes from uraemic patients to determine whether renal failure in any way impairs the performance of this means of defence against infection.

Two mechanisms of phagocytosis have been demonstrated in human polymorphs (Brogan, 1966): one is independent of serum and the other is conditional on the presence in the cell environment of serum factors. The present inquiry was designed to examine various aspects of these two mechanisms of phagocytosis in uraemic patients and to compare the findings with those in a group of patients whose renal function was normal.

\section{Materials and Methods}

Patients.-Twelve uraemic patients were studied, the majority of whom were in chronic renal failure from a variety of causes, details of which are listed in Table I. In parallel, a series of 17 hospital inpatients with normal kidney function were investigated; almost $50 \%$ were suffering from myocardial infarction, and the rest were under treatment for a variety of conditions (Table I). All patients of the control group had a normal blood urea, and their polymorphs were examined during the recovery or quiescent phase of their illnesses.

TABLE I.-Patients : Clinical Data. Levels of Blood Urea Were Those Recorded at Time of Taking Blood for Testing Phagocytic Activity

\begin{tabular}{|c|c|c|c|c|}
\hline \multicolumn{3}{|c|}{ Group with Renal Failure } & \multicolumn{2}{|c|}{ Group with Normal Renal Function } \\
\hline $\begin{array}{l}\text { Case } \\
\text { No. }\end{array}$ & Diagnosis & $\begin{array}{c}\text { Blood } \\
\text { Urea } \\
\text { (mg.l } \\
100 \mathrm{ml} .)\end{array}$ & $\begin{array}{l}\text { Case } \\
\text { No. }\end{array}$ & Diagnosis \\
\hline $\begin{array}{c}1 \\
2 \\
3 \\
4 \\
5 \\
6 \\
\\
\times \\
10 \\
11\end{array}$ & $\begin{array}{l}\text { Chronic membranous } \\
\text { glomerulonephritis } \\
\text { Chronic urinary retention } \\
\text { Polycystic kidneys } \\
\text { Cystinuria } \\
\text { Renal calculi; chronic } \\
\text { pyelonephritis } \\
\text { Cystinuria; renal calculi } \\
\text { Chronic pyelonephritis } \\
\text { " } \\
\text { Chronic urinary retention } \\
\text { hladder diverticulum } \\
\text { Staphylococcal septicaemi } \\
\text { precipitating acute renal } \\
\text { failure } \\
\text { Acute glomerulonephritıs } \\
\text { of late onset }\end{array}$ & $\begin{array}{l}400 \\
300 \\
280 \\
250 \\
350 \\
180 \\
260 \\
300 \\
405 \\
395 \\
122 \\
\\
440\end{array}$ & $\begin{array}{l}1-8 \\
9 \\
10 \\
1112 \\
13 \\
14 \\
15 \\
16 \\
17\end{array}$ & $\begin{array}{l}\text { Myocardial infarction } \\
\text { Anxiety state } \\
\text { Fpilepsy of late onset } \\
\text { Pyrexia of uncertain origin } \\
\text { prug overdose } \\
\text { Idiopathic steatorrhoea } \\
\text { Bronchiectasis } \\
\text { Spontaneous pneumo- } \\
\text { thorax } \\
\text { cute anpendicit }\end{array}$ \\
\hline
\end{tabular}

